\title{
Performance Evaluation for Faculty Members at SETIF University (02) According to the Quality Assurance Standards from Their Point of View
}

\author{
Khaoula Kachaou \\ Educational Sciences - Humanities \\ and Social Sciences \\ Abu Al-Qasim Saadallah \\ University, Algeria (2) - Algeria \\ Khaoulakach@gmail.com
}

\author{
Nabil Bahri \\ Educational Sciences - Humanities \\ and Social Sciences \\ Abu Al-Qasim Saadallah University \\ Algeria (2) - Algeria \\ azaghar70@gmail.com
}

\author{
Hocine Bachioua \\ Psychology, educational sciences \\ - and orthophony \\ University of Mohamed Lamine \\ Dabbaghine Setif (2) - Algeria \\ bachiouahocine@gmail.com
}

Received 11/6/2020

Accepted 2/7/2020

\begin{abstract}
:
This study discusses the evaluation of the professor's performance in the field of teaching, scientific research, and community service depending on the quality assurance standards from their point of view.

The purpose is also to show the indication of differences in the level of performance according to the variables of sex, academic level, and the faculty where they work. For this study, the descriptive method is used.

The sample study contains (185) faculty members in the University of SETIF (02) for the school year (2019/2020), where a questionnaire is designed and is formed of (45) points divided into three units: (teaching, scientific research, and community service). The «Statistical Packages for the Social Sciences» (SPSS) is used for data processing.

The findings show that the level of performance for the faculty members in the fields of teaching, sciresearch, and community service depending on the quality assurance standards is normal/medium.

The study also shows that there are no significant differences in the level of teacher's performance in the (3) previous domains due to the variable of sex and faculty of specialization. Whereas there are statistically significant differences due to the variable of the academic level in the domain of scientific research for university teachers.
\end{abstract}

Keywords: Evaluation, Performance, University Professor, Quality Assurance, Standards. 


\section{تقييم الأداء الوظيفي لأعضاء هيئة التدريس بجامعة سطيف (2) في ضوء معايير ضمان الجودة من وجهة نظرهم}

\author{
حسين باثشيوة \\ علم النفس وعلوم التربية والارطفونيا - \\ العلوم الإنسانية والاجتماعية \\ جامعة محمد لمين دباغين سطيف (2) \\ bachiouahocine@gmail.com
}

قبول البحث 2020/7/2

\author{
نبيل بحري \\ علوم التربية - العلوم الإنسانية \\ والاجتماعية \\ جامعة أبو القاسم سعد الله الجزائر (2) \\ azaghar70@gmail.com
}

\author{
خولة قثناو \\ علوم التربية - العلوم الإنسانية \\ والاجتماعية \\ جامعة أبو القاسم سعد الله الجزائر (2) \\ Khaoulakach@gmail.com
}

استلام البحث 2020/6/11

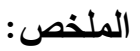

تناقش هذه الدراسة تقييم الأداء الوظيفي للأستاذ الجامعي في مجال التدريس، البحث العلمي، وخدمة المجتمع وفق معايير ضمان الجودة من وجهة نظرهم، والكثف عن دلالة الفروق في مستوى الأداء وفقاً لمتغيرات الجنس، المستوى الأكاديمي، الكلية التي يعملون فيها، وقد تم استخدام المنهج الوصفي وشملت عينة الدراسة (185) عضو هيئة تدريس بجامعة سطيف (2) للعام الدراسي (2020/2019)، حيث تم تصميم استيان مكون من (45) بندا موزعين على ثلاثة محاور (التدريس، البحث العلمي، خدمة المجتمع) ولمعالجة بيانات الدراسة تم استخدام برنامج الحزم الإحصائية للعلوم الاجتماعية (SPSS). أظهرت نتائج البحث أن مستوى الأداء الوظيفي لأعضاء هيئة التدريس في مجال التدريس، البحث العلمي وخدمة المجتمع في ضوء معايير

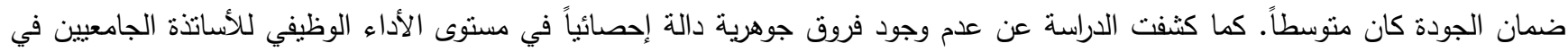

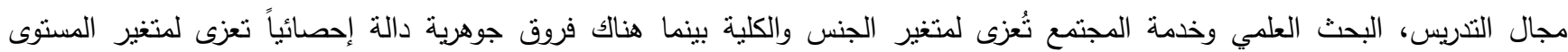

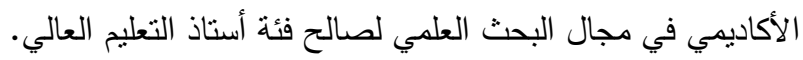
الكلمات المفتاحية: تقييم، الأداء الوظيفي، عضو هيئة التخريس، ضمان الجودة، المعايير.

المقدمة:

التكوين مما فرض الكثير من التغييرات والتعديلات على الممارسات

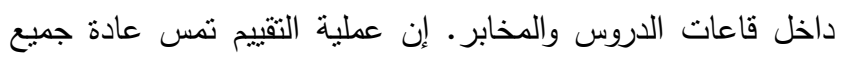

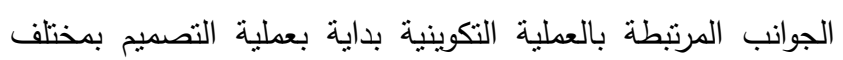

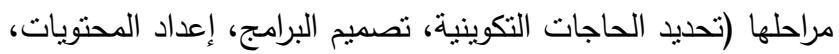

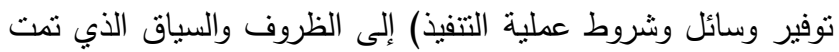
فيه عملية التتفيذ إلى المخرجات المنوصل إليها. كما يجب لعملية التقييم أن نتمل أيضاً أعضاء هيئة التدريس الذين يمنلون محوراً

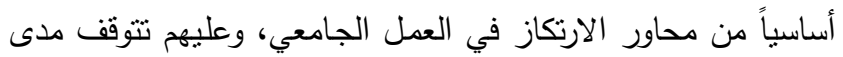
كفاية التعليم الجامعي وجودته، إذ من خلارل سمعتهم ومكانتهم

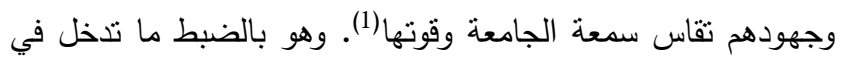

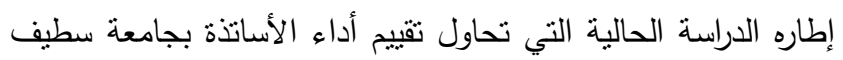
(2) وهذا في إطار نظام تسييري يعتبر فيه التقييم ركن الزاوية وهو
لقد حاول العديد من الباحثين تحديد مفهوم الأداء الوظيفي

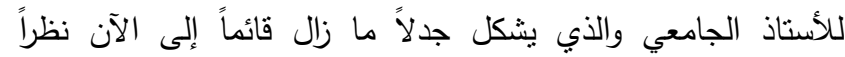

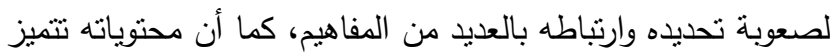
بالديناميكية نظرًا لتغير وتطور مواقف وظروف المؤسسات بسبب تغير ظروف وعوامل بيئتها الداخلية والخارجية على حد سواء. كما يرتبط مفهوم الأداء بسلوك الفرد والمنظمة، ويحتل مكانة خاصة داخل أية مؤسسة باعتباره الناتج النهائي لمحصلة جميع الأنشطة بها. بذلت الجامعة الجزائرية جهودا كبيرة لتطوير أنظمتها وتحديثها

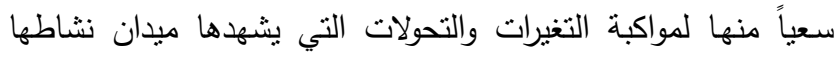

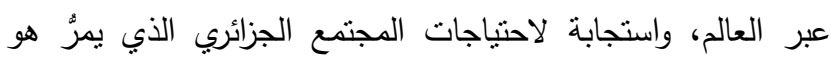

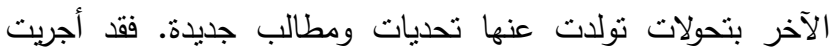
الكثير من التغييرات والإصلاحات تضمنت إعادة النظر في هيكلة التعليم العالي، وعروض وبرامج النكوين، وحتى وسائل واستراتيجيات 
التقييم الخاصة بالطلبة، وفي المجال البحثي يشيرون إلى عدم معالجة

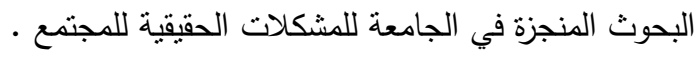
وما ينبغي أن نستقيد منه في مدخل ضمان لمكان الجودة في التعليم

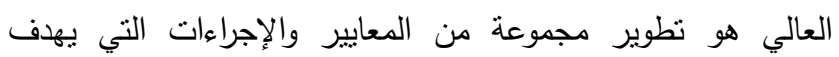
تتفيذها إلى التحسين المستمر في المنتج التعليمي تحقيقا للجودة، وهو ما تم وضعه من خلال المرجع الوطني لضمان الجودة، وتتثبر الدراسات المتعلقة بهذا الدجال إلى أنّ نظام ضمان الجودة في النعليم العالي يعمل على نطوير جميع جوانب العمل الإداري والأكاديمي

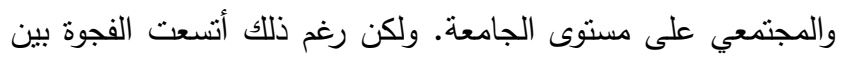

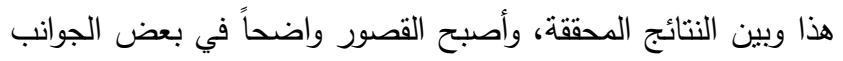

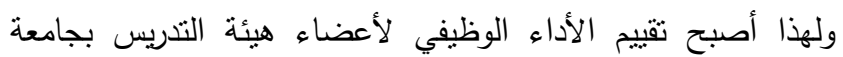
سطيف (2) في ضوء معايير ضمان الجودة من وجهة نظرهم ضرورة

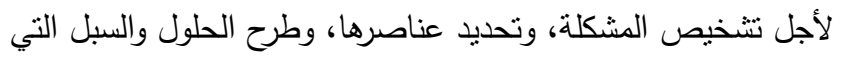
تحصن الجامعة في الوقوع في مثل هذه المشاكل . تسعى الدراسة الحالية إلى الإجابة عن التساؤلين التاليين: ما لإهناء مستوى الأداء الوظيفي لأعضاء هيئة التدريس بجامعة محمد لمين الإنها دباغين سطيف (2) في مجالات التدريس، البحث العلمي وخدمة المجتمع في ضوء معايير ضمان الجودة من وجهة نظرهم؟ هل توجد فروق ذات دلالة إحصائية في استجابة افراد عينة الدراسة تُعزى فئن لمتغيرات الجنس والمستوى الأكاديمي والكلية التي يعملون فيها؟؟ دلهابه وسنحاول من خلال هذه الدراسة تحقيق مجموعة من الأهداف منها:

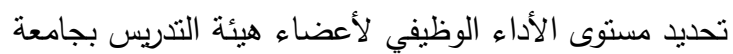
محمد لمين دباغين بجامعة سطيف (2) في مجالات التدريس، البحث العلمي، وخدمة المجتمع في ضوء معايير ضمان الجودة من وجهة نظرهم. الكثف عن دلالة الفروق في استجابات أفراد العينة حول

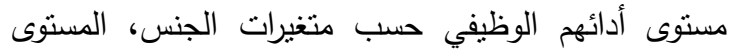

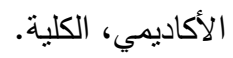

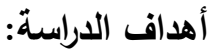

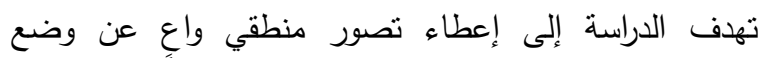
مؤسسات التعليم العالي على مسنوى الوزارة الوصية، وتِقييم الأداء الوظيفي لأعضاء هيئة التدريس بجامعة سطيف (2) في ضوء معايير ضمان الجودة من وجهة نظرهم لوضع خطط علاجية لمكافحتها والحدّ لإِ من القصور ، وتوفير اللازم من خلال توطين نماذج التجارب الناجحة، ومعالجة العقبات المنوقعة، وتبعاتها خلال السنوات القادمة.

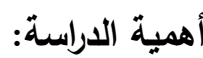

تعد هذه الدراسة مهمة نظراً لموضوعها وأيضاً لأجل استكمال الدراسات التي تتاولت هذا الموضوع سواء على المستوى الدراسات

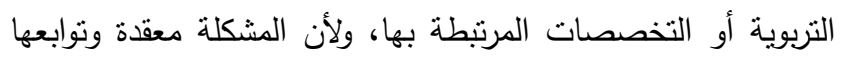

نظام ضمان الجودة والذي تعتمده كل المؤسسات التي تصبو إلى تحقيق الأهداف التي نسطرها لنفسها.

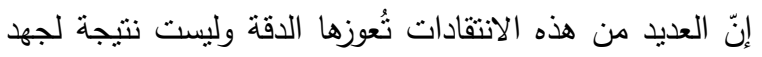

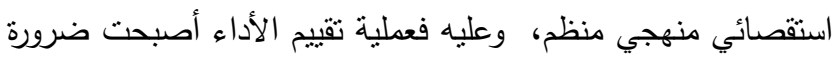
حتمية للوقوف على نقاط القوة والتميز ونقاط الضعف، لاسيما وأن

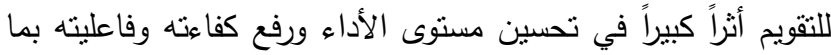
يضمن جودة التعليم بالجامعة الجزائرية، فمن خلالهه نتعرف على مدى الادى

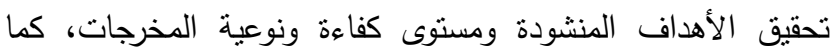
تشكل التغذية الراجعة عن التقييم مدخلاً أساسياً في نطوير أداء الأستاذ وأسلوب ندريسه ومنهجه مما ينعكس إيجابا على العملية العابها

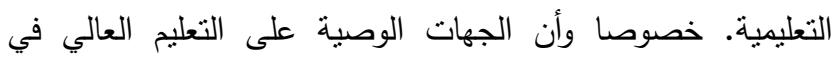

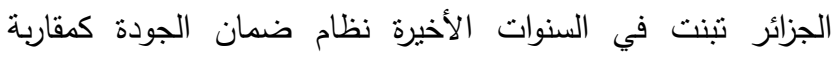
للتطوير والتحسين والني يمنل التقييم فيها المكون الرئيسي. فمنذ ماي 2010م، تمّ نرسيم عمل الفرقة بصدور القرار الوزاري رقم 167 المنضمن تأسيس لجنة وطنية لتطبيق نظام ضمان الجودة في النعليم العالي وذللك بهدف دعم وتتشيع مؤسسات التعليم العالي، على نطبيق أحسن الممارسات سواء على المستوى المؤسسي أو البرامجي(19).

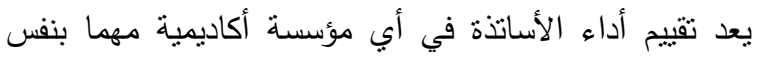
أهمية تقييم التعلم لدى الطلبة، فهم مسئولون عن العملية التعليمية،

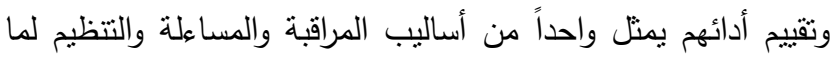
يقومون به داخل المؤسسة التعليمية. فعن طريق البيانات الني ينت تجميعها يمكن تحديد نقاط القوة والضعف التي نستخدم كأساس للتحسين والتطوير ليس فقط للأساتذة ولكن أيضاً للمؤسسة التعليمية بشكل عام من حيث رسم السياسات في توظيف الأساتذة والتطوير المهني. كما يمكن أن نوفر البيانات المستقاة من تقييم الأساتذة صورة

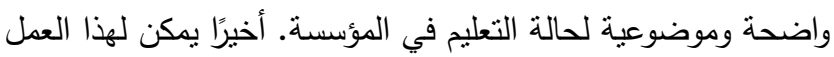
أن يساعد أيضا في تحديد الدرجة التي تلبي بها المؤسسة التعليمية

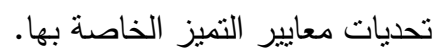

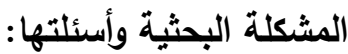

يوجه المتابعون لواقع التعليم بالجامعة الجزائرية الكثير من

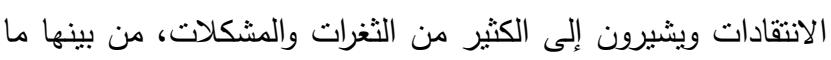
يتعلق بالتأطير من عدم كفاية الأساتذة في بعض التخصصات ونقص التصن

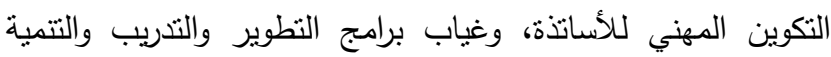
المهنية، بالإضافة إلى قيام بعض الأساتذة بندريس مواد غير متمكنين لونين

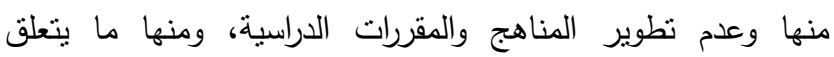
بالممارسات داخل قاعة الدراسة إذا يشيرون إلى شئيوع الأساليب التقليدية في التدريس وعدم الاهتمام بالأساليب المصحوبة باستخدام

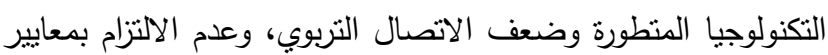


ومدى حاجة الموظف والتوجيه من قبل المشرفين وتقييم

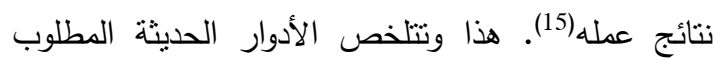

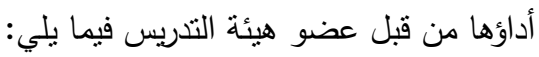

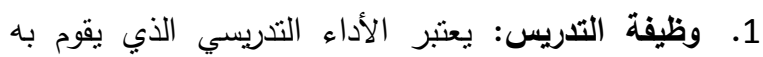
الأستاذ من أهم الدذخلات في تحقيق الأهداف التربوية، كما بعتبر المؤثر القوي في إحداث التغيرات المطلوبة لدى الدى

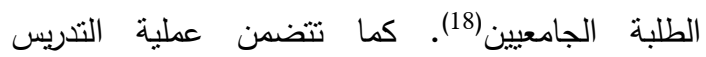

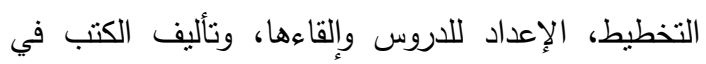

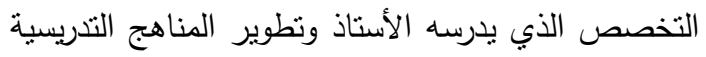

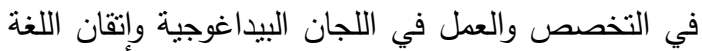

\section{في تدريسها.}

2. البحث العلمي: حيث بمثل البحث العلمي الركيزة الأساسية

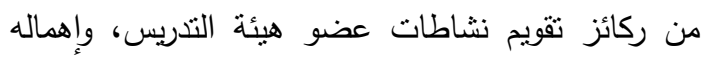
للبحث العلمي سيؤدي إلى ضعف العملية التدريسية، ومن لهن وظائف البحث العلمي الذي يقوم به الأستاذ الجامعي:

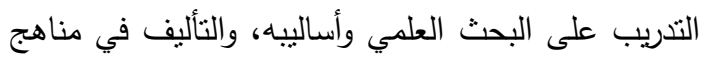

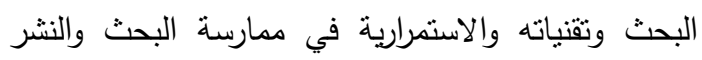

$$
\text { العلمي في ميدان التخصص. }
$$

3. خدمة المجتمع: وذلك من خلال المساعدة على حل المشكلات التي يعانيها المجتمع سواء كانت اجتماعية أو هل

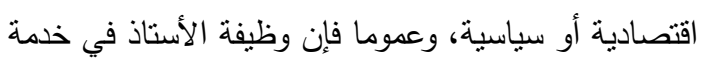
المجتمع وتتميته تتم من خلال ما يقوم به: • داخل الجامعة: وتتضمن المشاركة في الأنشطة الطلابية الثقافية والفنية والرياضية وإلقاء المحاضرات في موضوعات علمية متتوعة في ولئة

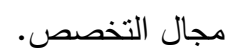

خارج الجامعة: كالقيام ببحوث لصالح المشكلات

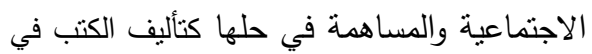
مجال التخصص. المشاركة في الندوات العلمية التي تنظمها قطاعات غير جامعية بتقديم أعمال

$$
\text { علمية مهمة فيها (6). }
$$

4. الإدارة الأكاديمية: حيث تختلف مسؤوليات أساتذة الجامعة

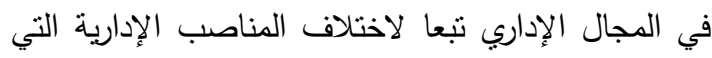
يشغلها هؤلاء المدرسون، كما تتمثل ممارساتهم في العملية الإدارية في التتظيم والتخطيط والإنشراف والرقابة والاتصال والتواصل بطريقة سليمة تراعي الحداثة في الأسلوب القيادي كالديمقراطية، واستخدام نماذج حديثة في القيادة كالإدارة

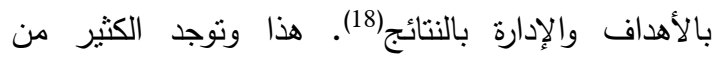
الأساليب والطرق التي يتم بها تقييم واستكثاف أداء الأساتذة والتي تتفاوت في فعاليتها، ولأن المجال لا ينسع الأنس
مكلفة، ومن هنا تنبثق أهية هذه الدراسة، إذ يشكل تقييم الأداء الوظيفي لعضو هيئة التدريس أساساً لضمان جودة العملية التعليمية التهاه

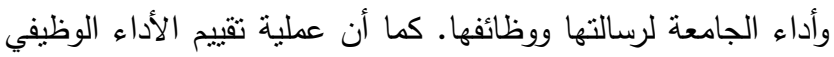

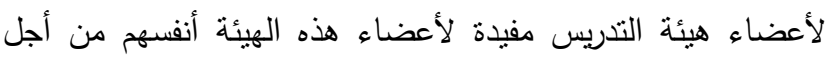
نطوير وتحسين الطرق والمبادئ التربوية التي بستخدمونها، وذلك من لان التهن خلال التعرف على مواطن القوة والضعف، بما يحقق أهداف العملية

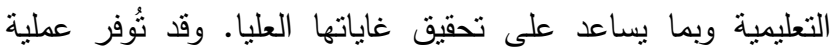

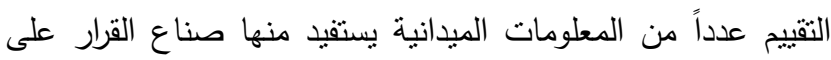
المستوى المحلي (مسئولو الجامعات) أو الوطني (الوزارة الوصية).

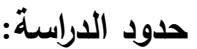

تتحدد هذه الدراسة بكليات العلوم التربوية والأقسام المرتبطة بها

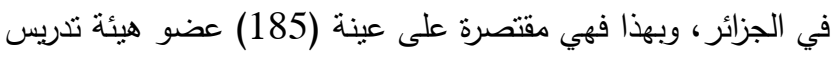
بجامعة سطيف (2)، وأيضاً الدراسة محددة بالمواد العلمية المتاحة لدراسة موضوع هذه الدراسة، وفي المدة الزمنية 2020/2019م.

\section{التعريفات المفاهيمية والإجرائية للاراسة:}

تحتاج الدراسة إلى ضبط بعض المصطلحات الأساسية الني تعددت تعريفات الباحثين لها لأجل الاستفادة منها وتسهيل عملية

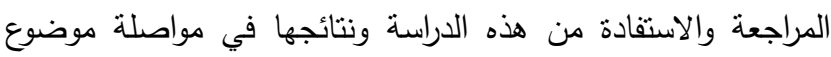

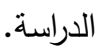

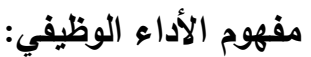

يُعرّف الأداء الوظيفي على أنه القيام بأعباء الوظيفة من الون

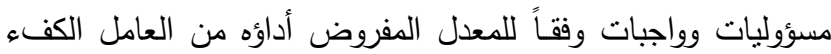
المدرب(10)، كما يعرف أيضا على أنه: تتفيذ الموظف لألمات لأعماله ومسؤولياته التي تكلفه بها المنظمة أو الجهة الني ترنبط وظيفته بها، ويعني النتائج التي يحققها الموظف في المنظمة (16). أمّا الأداء الوظيفي لعضو هيئة التدريس فيمكن القول: إنّه ذلك فئي

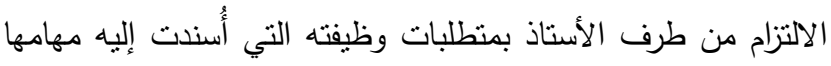

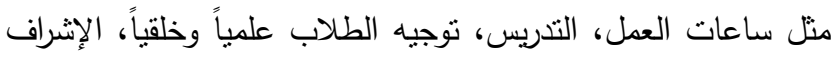
على بحوث الطلبة ونثاطاتهم العلمية، القيام بواجبه العلمي في ميادين البحث والتوجيه الإداري وخدمة المجتمع وكذا الالتزام بأنظمة الجامعة

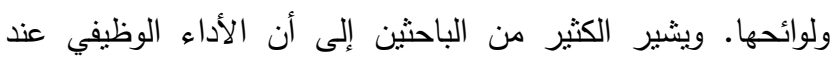

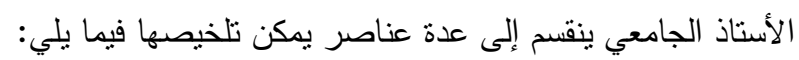
• المعرفة بمتطلبات الوظيفة: وتتشل المعارف والمهارات الفنية والخلقية العامة عن الوظيفة والمجالات المرتبطة بها.

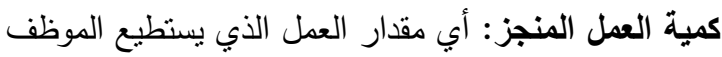

إنجازه في الظروف العادية ومقار سرعة هذا الإنجاز. • المثابرة والوثوق: وتتشمل الجدية والتفاني في العمل والقدرة على تحمل مسؤولية العمل وإنجازه في الوقت المحدد، 
الجامعة من خلال المهام والوظائف الحيوية التي يشغلها خاصة ما يرتبط منها بالتدريس والبحث العلمي وخدمة المجتمع. وعليه بأتي تقييم الأداء الوظيفي للأستاذ الجامعي ضمن أولويات عملية تقييم الأداء

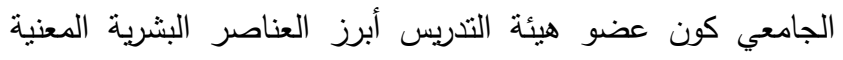

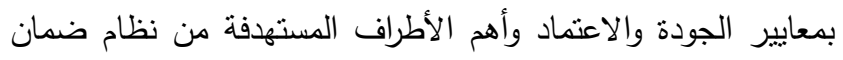

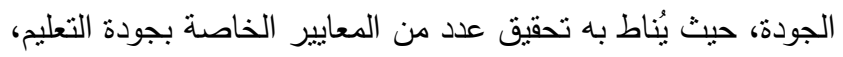

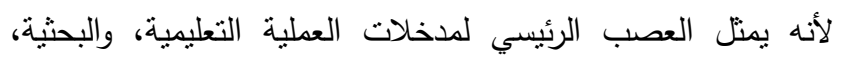

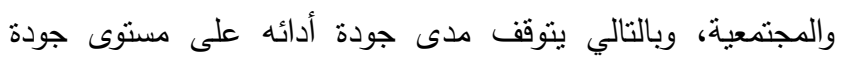

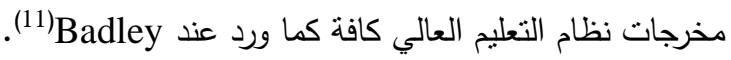
وفي نفس سياق الدراسات أعلاه أثنار هالينجر (Hallinger)

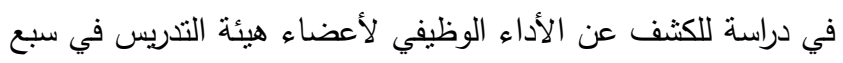

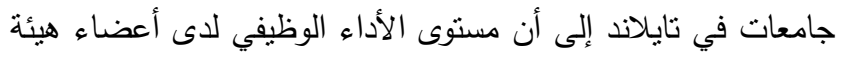

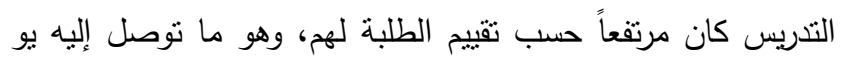
وهامير وايجاد (Yum Hamis \& Ijad) (1) في دراستهم لتقييم الأداء الوظيفي لأعضاء هيئة التدريس في الجامعات الماليزية، إذ أنثارت

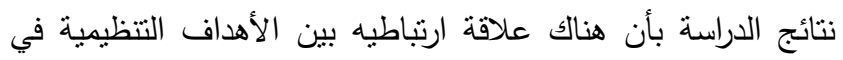

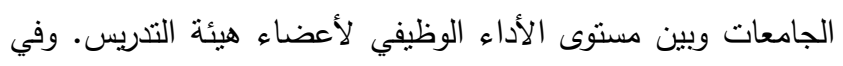

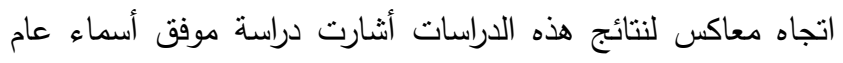
(2015)(17)، إلى انخفاض مسنوى جودة الأداء التنريسي للأستاذ

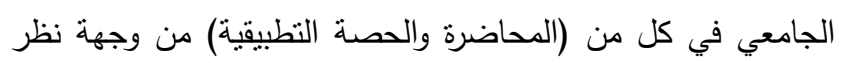

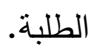

ومن هذا المنطلق تُعرّف المنظمة الدولية للمعايرة ISO ضمان

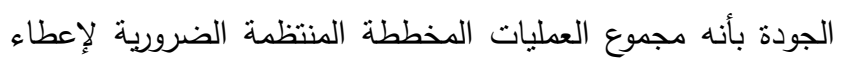

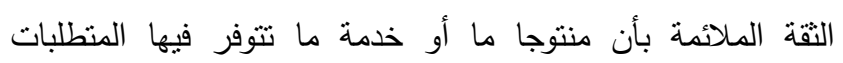

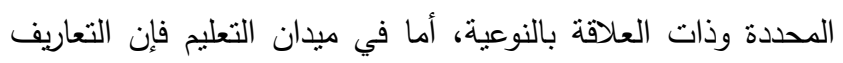

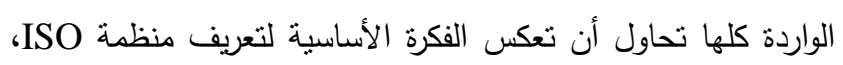

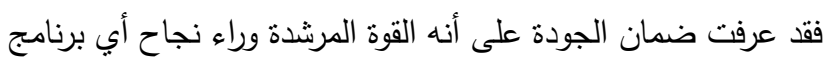

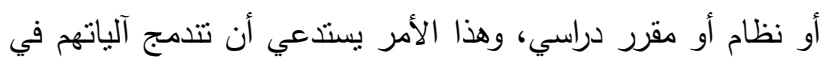

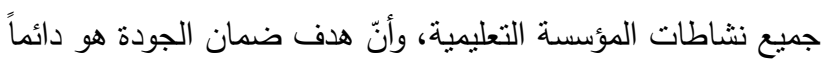
تفادي وقوع الأخطاء ومنع الفشل(4).

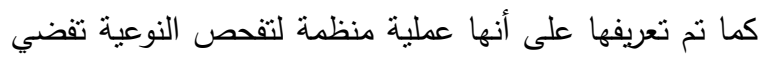

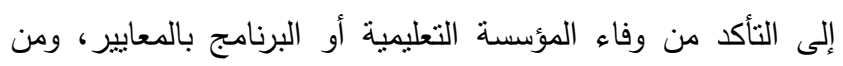

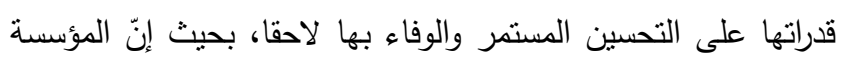
تضمن الجودة لنفسها، وبحيث إنّ الجهة الخارجية تضمن للجمهور

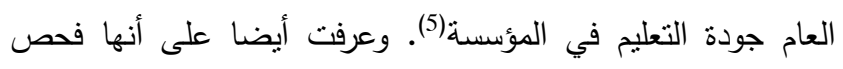

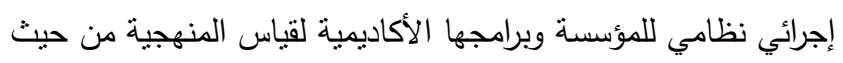
مناسبة الترتيبات المخططة لتحقيق أهدافها، والنطبيق من حيث نوافق التقادئ

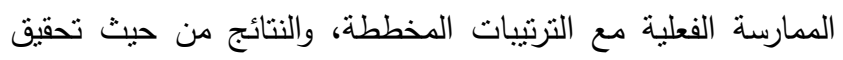

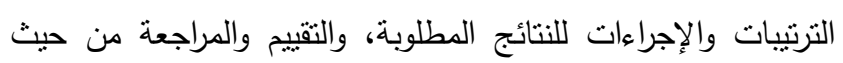

للخوض فيها فإننا نكتفي باستعراض ما يقترحه مدخل

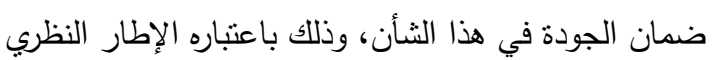

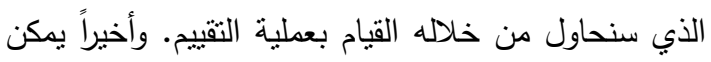
القول إنّ ضمان الجودة مصطلح يغطي الاجراءات المتخذة

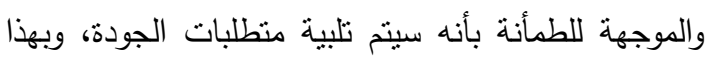
بمكن للمؤسسة التعليمية أن تضمن أنها تطبق نظانهاً يكثف، ويقبس، ويصحح الخلل الكامن المكن، وأنها تقوم

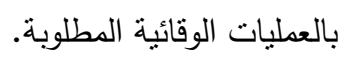

\section{الإطار النظري والدراسات السابقة والتعقيب عليها:}

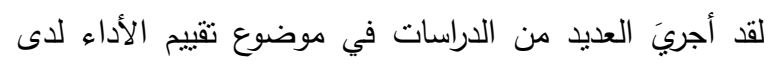

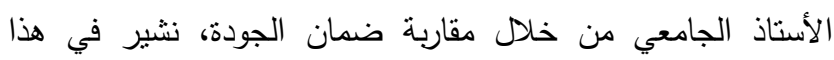

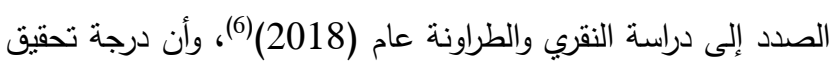

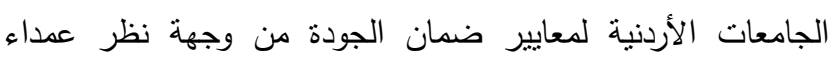
الكليات ورؤساء الأقسام الأكاديمية فيها كانت مرتفعة، وأن هناك فروقاً

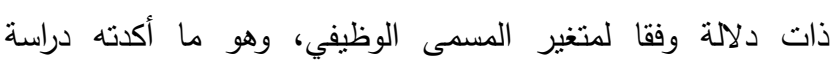

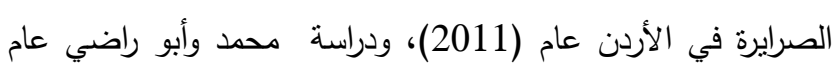

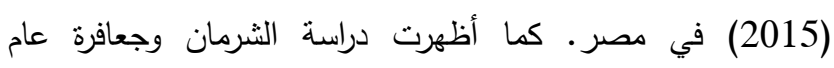

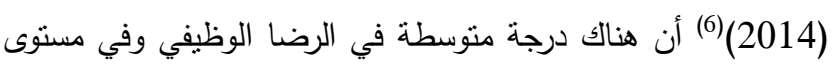

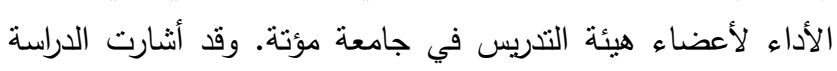

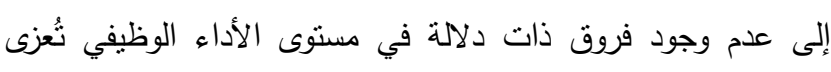

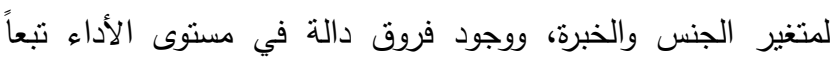

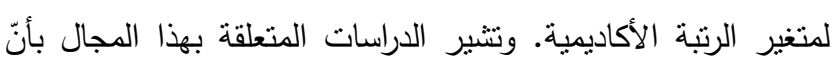

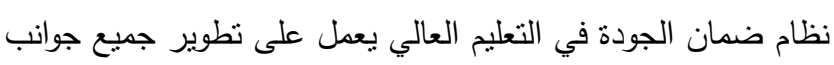

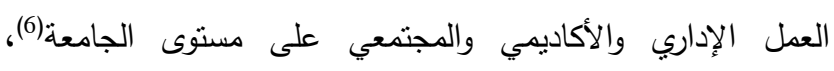

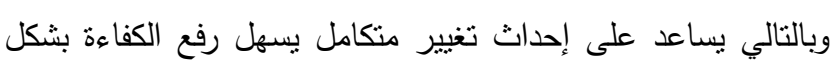
عام.

وكفاءة عضو هيئة التدريس بشكل خاص وفاعليته هما الركيزة الأساسية التي تقوم عليها الجامعة من خلا المهام والوظائف الحيوية

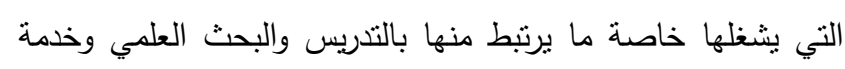

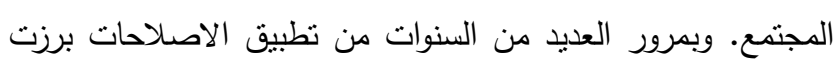

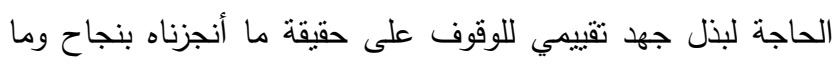

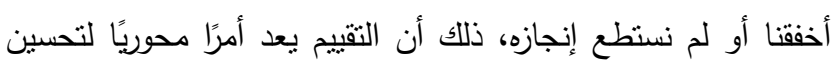

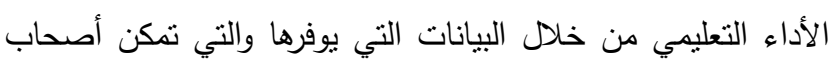

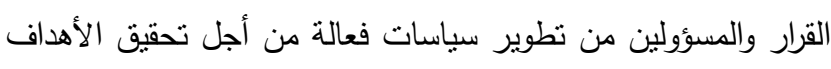
الوطنية، كما يساعد الممارسين في الميدان من إحداث التغييرات والتعديلات الضرورية لتحسين أدائهم ونطويره. إنّ التحسين المستمر في المنتج التعليمي بساعد على إحداث

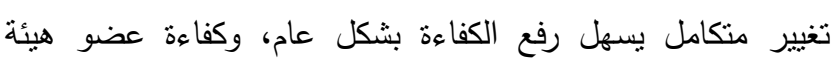
التدريس بشكل خاص ذلك أنّه الركيزة الأساسية التي نقوم عليها 
المحصل عليها لوضح خريطة تشخيصية استرشادية لنطوير مستوى منتجات أعضاء هيئة التدريس.

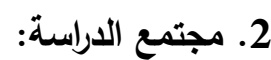

بما أن هدف الدراسة هو تحديد مستوى الأداء الوظيفي لأعضاء هيئة التدريس بجامعة محمد لمين دباغين سطيف في ضون هوف معايير ضمان الجودة من وجهة نظرهم، فإنّ مجتمع الدراسة هو بالضرورة جميع أعضاء الهيئة التدريسية بجامعة محمد لمين دباغين في الكليات الثلاث: كلية العلوم الإنسانية والاجتماعية، وكلية الآداب واللغات الأجنبية، وكلية الحقوق والعلوم السياسية من الذكور والإناث حيث بلغ الإنية

$$
\text { عددهم(765) أستاذاً وهو المجتمع الإحصائي للدراسة. }
$$

\section{3. عينة (لاراسة:}

تم اختيار العينة في هذه الدراسة من الكليات الثلاث بطريقة

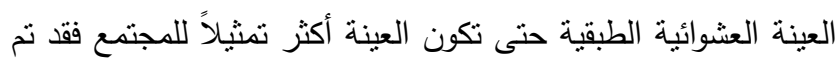
اختيار نسبة (30\%) من المجتمع الكلي والمتكون من (765) أستاذا

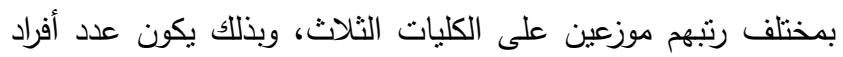
عينة الدراسة (230) في الكليات الثلاث الذين تم توزيع الاستنيان عليهم إلا أنه ثم استرجاع (200) استنيان ولكن استبعد (15) استبياناً

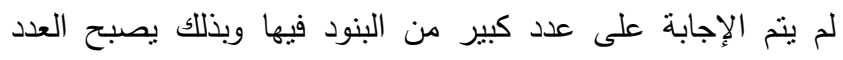

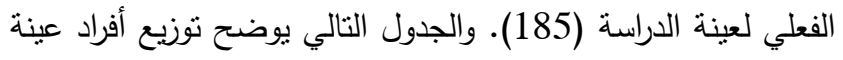

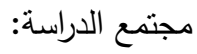

جدول رقم (01): يوضح توزيع مجتمع الدراسة.

\begin{tabular}{|c|c|c|}
\hline النسبة المئوية \% & العدد الإجمالي للأساتذة & الكلية \\
\hline 44.05 & 337 & العلوم الإنسانية والاجتماعية \\
\hline 29.80 & 228 & الآداب واللغات الأجنية \\
\hline 26.14 & 200 & الحقوق والعلوم السياسية \\
\hline 100 & 765 & المجموع \\
\hline
\end{tabular}

المصدر : من إعداد الباحثين.

\section{4. أدوات الدراسة وإجراءات بنائها:}

اعتمدت هذه الدراسة على الاستيبان الذي بعد من بين الأدوات

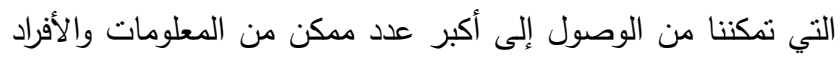

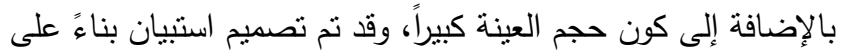
ما ورد في الأدب النظري والدراسات السابقة التي نتاولت متغيرات الدراسة وقد تكونت الأداة من جزيني: الجزء الأول، شمل متغيرات الدراسة وهي: الجنس والرتبة الأكاديمية والكلية التي ينتمي إليها، أما

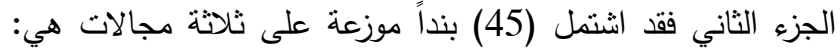

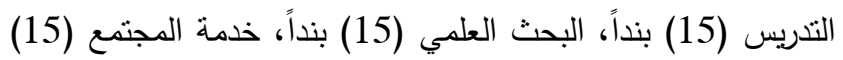

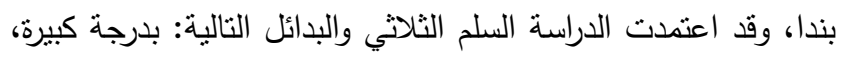
بدرجة متوسطة، بدرجة ضعيفة، أما الأوزان فكانت كالتالي: بدرجة اعتدان كبيرة (3)، بدرجة منوسطة (2)، بدرجة ضعيفة (1). وقد نم حساب
قيام المؤسسة بالتعلم والتحسين من خلال تقييمها الذاتي للترتيبات والطرق والتنفيذ والنتائج(1). تقع مهام تحقيق أهداف الجامعة بالدرجة الأولى على عانق

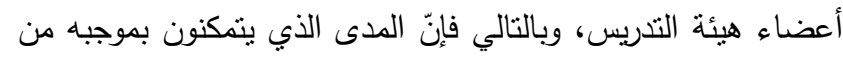
القيام بتتفيذ خطط وبرامج تحقيق تلك الأهداف يشير إلى فاعليتهم

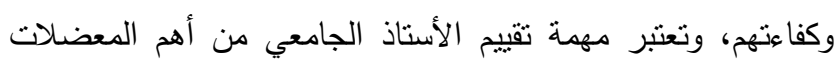

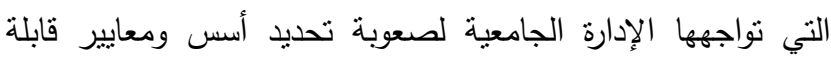

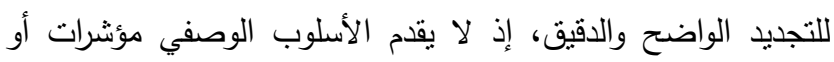

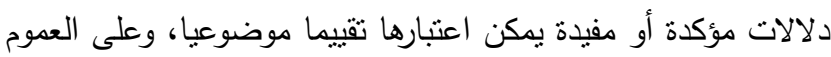

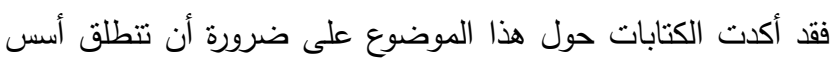

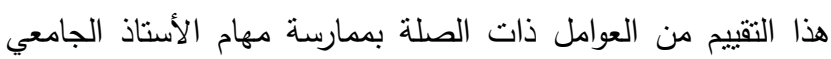

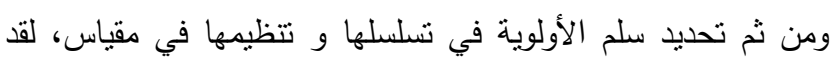

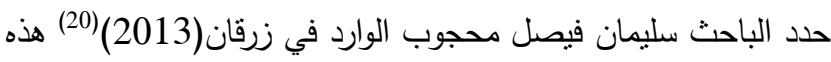
المعايير التي نكتفي هنا بذكر محاورها الرئيسية:

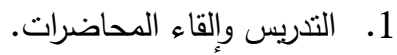
2. البحث العلمي إعدادا وتأطيرا. 3. الارشاد التزبوي والعلاقة مع الطلبة. 4. المهام الإدارية والعلاقة مع الادارة. 5. خدمة المجتمع والعلاقة مع حقل العمل. 6. النشاط الاجتماعي والعلاقة مع الزملاء.

استعرضت هذه الدراسة دراسات سابقة منتوعة جغرافيا، وفي مواضيع تطبيق أساليب تقييم الأداء الوظيفي لأعضاء هيئة التدريس

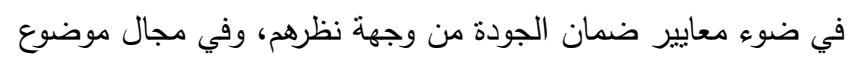

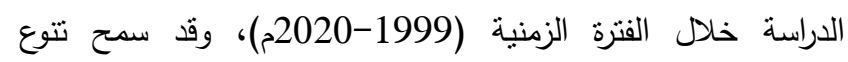
الدراسات في موضوعاتها وأهدافها ونتائجها إلى اشتقاق كل العناصر الخاصة بنطبيق المنهجية على مشكلة موضوع الدراسة، والاسترشاد بنتائجها، وقد سمح للباحث في تحقيق أهداف الدراسة.

الدراسة الميدانية وتحليل نتائجها:

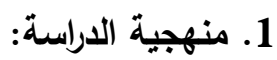

اعتمدت الدراسة على المنهج الوصفي التحليلي كونه أكثر التراسهر ملائمة بالنظر لطبيعتها وتحقيق الأهداف المرجوة من تقييم الأداء الوظيفي لأعضاء هيئة التدريس، وتثخيص الخلل على مستوى الأداء

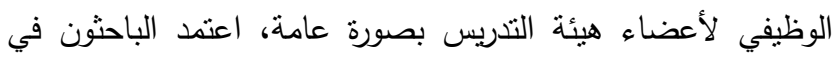

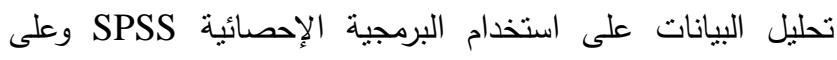
مجموعة من الأدوات الإحصائية المرافقة لها مثل تحليل النسب الإنب

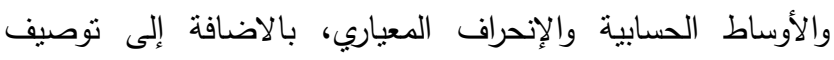
بيانات الدراسة وتحليلها عبر الأساليب الإحصائية الدكملة الأخرى.

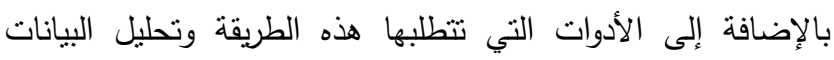


تقييم الأداء الوظيفي لأعضاء هيئة التدريس بجامعة سطيف (2) في ضوء معايير ضمان الجودة من وجهة نظرهم.

المرتبة الأخيرة بمستوى متوسط أيضا لكن بمتوسط حسابي قدره

(1.75) ونسبة مئوية قدرها (58.33).

من خلال استعراض النتائج المتحصل عليها من بيانات الجدول

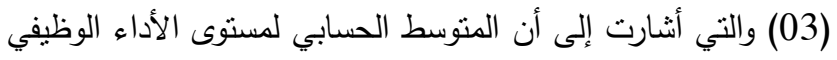

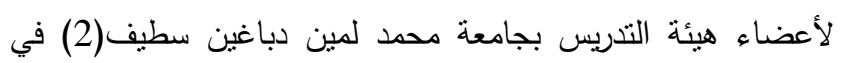
مجالات (التدريس، البحث العلمي، وخدمة المجتمع) على أداة الدراسة

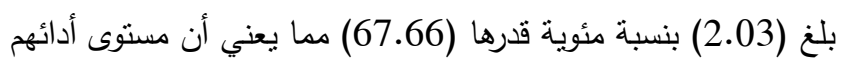
الوظيفي من وجهة نظرهم كان متوسطا. هذا ومن الفقرات التي حصلت على متوسطات حسابية عالية، الفقرات (25، 6، 2، 24) حيث حصلت الفقرة رقم (25) في مجال البحث العلمي والتي نصت على التى "تثارك في الندوات، الملتقبات والمؤتمرات العلمية "على أعلى منوسط حسابي قدره (2.84) ونسبة

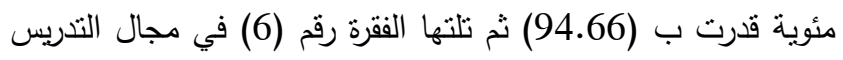
والتي تتص على "تدير وقت الدحاضرة بكفاءة" بمتوسط حسابي قدره

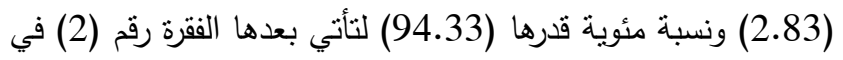
مجال التدريس والتي تتص على ولى "تعتمد على المراجع الحديثة في إعداد الخطة الدراسية لضمان جودتها" بمنوسط حسابي قدره (2.82) ونسبة مئوية بلغت (94) ثم الفقرة رقم ( 24) ـ وفي مجال البحث

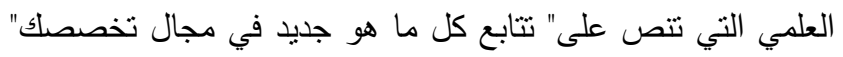
بمنوسط حسابي قدره (2.81) ونسبة مئوية (93.66)، بينما الفقرات التي تحصلت على أدنى الكتوسطات الحسابية فهي الفقرات (41، ونة 36، 11، 45) على التوالي حيث تحصلت الفقرة رقم (41) في مجال خدمة المجتمع والتي تتص على "تتابع خريجي الجامعات في مواقع العمل والإنتاج لتوجيهم" على متوسط حسابي قدره (1.18) ونسية

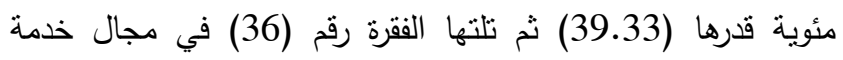
المجتمع والتي تتص على " تثارك بالكتابة في وسائل الإعلام المختلفة التي تخدم المجتمع" بمتوسط حسابي بلغ (1.19) ونسبة مئوية بلغت (39.66) لتأتي بعدهما الفقرة رقم (11). وفي مجال التدريس والتي تتص على "تثنلك القدرة على تصميم المقررات الدراسية الإلكترونية" حيث بلغ متوسطها الحسابي (1.25) ونسبة مئوية قدرت ب(41.66) في حين بلغ المتوسط الحسابي للفقرة

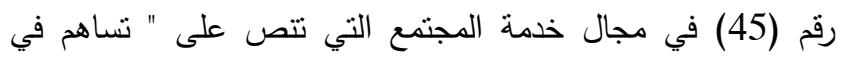

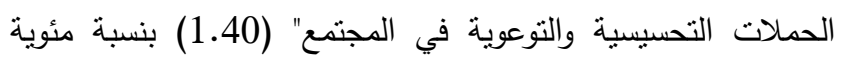
قدرها (46.66). هذا ويمكن أن تقرأ هذه النتيجة عدة قراءات أهدها: أن مدخل ضمان الجودة أسلوب جديد لم تتوصل الجزائر بعد لتنبنيه بالثكل المطلوب في نظامها الجامعي وذلك لضعف نهيئة منطلبات هذا المدخل وعدم وضوح سياسة تطبيق نظام ضمان الجودة، كما قد

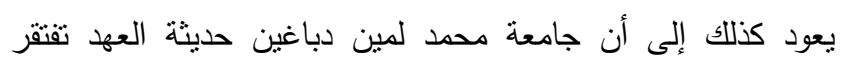

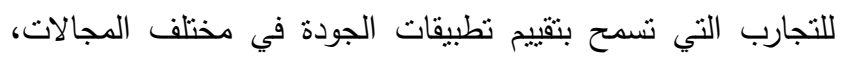

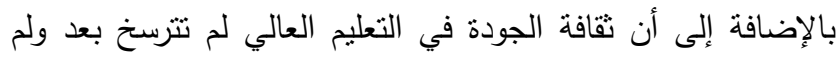

الثروط السيكومترية للأداة وكانت مناسبة، وقد تمت معالجة بيانات

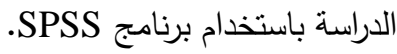

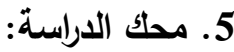

لتفسير بيانات الدراسة استخدم الباحثون المحك التالي لتحديد

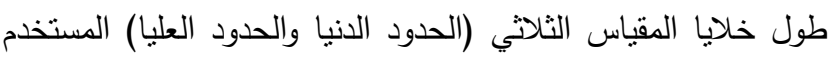
في محاور الدراسة، حيث تمّ حساب الددى ثم تقسيمه على عدد خلايا المقياس للحصول على طول الخلية الصحيح، بعد ذلك تم إضافة هذه القيمة إلى أقل قيمة في المقياس لتحديد الحد الأعلى لهذه الخلية، والجدول التالي يوضح حدود كل فئة.

جدول رقم (02): يوضح المحك المعتد في الدراسة.

\begin{tabular}{|c|c|c|}
\hline درجة الاستجابة & الأوزان النسبية & حدود الفئة \\
\hline ضعيفة & $55.33-33.33$ & [1.66-1] \\
\hline متوسطة & $77.66-55.66$ & [2.33- 1.67] \\
\hline كبيرة & $100-78$ & {$[3-2.34]$} \\
\hline
\end{tabular}

\section{6. عرض نتائج الدراسة الميدانية ومناقشتها:}

بعد استعادة الاستمارة ومراقبة مدى صلاحية البيانات الواردة

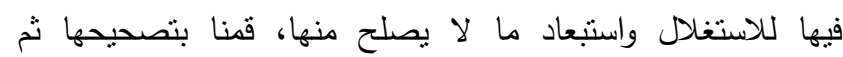

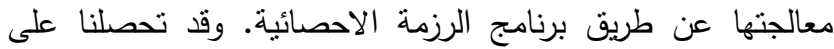

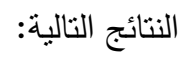

\section{1 عرض ومناقثة نتائج التساؤل الأول:}

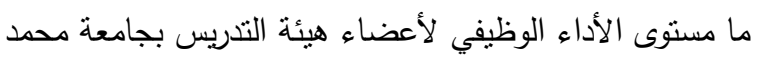
لمين دباغين سطيف (2) في مجال التدريس، البحث العلمي وخدمة المجتمع في ضوء معايير ضمان الجودة من وجهة نظرهم. تم حساب النسب المئوية والمتوسطات الحسابية ودرجة التحقق كما هو موضح

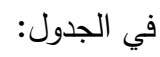
جدول رقم (03): يوضح نتائج عملية التحليل الإحصائي المتعلقة بالسؤال الأول.

\begin{tabular}{|c|c|c|c|c|c|}
\hline ترتيب المجالات & مستوى الاداء & المئوية & الحستوسي & المجال & الرقم الرق \\
\hline الاول & منوسط & 75 & 2.25 & البحث العلمي & 01 \\
\hline الثاني & منوسط & 69.66 & 2.09 & التدريس & 02 \\
\hline الثالث & منوسط & 58.33 & 1.75 & خدمة المجتمع & 03 \\
\hline & متوسط & 67.66 & 2.03 & \multicolumn{2}{|c|}{ الأداة ككل } \\
\hline
\end{tabular}
المصدر: من إعداد الباحثين.

يبين الجدول رقم (03) أن مستوى الأداء الوظيفي لأعضاء هيئة التدريس بجامعة سطيف (2) في مجال البحث العلمي كان متوسطاً حيث بلغ متوسطه الحسابي (2.25) ونسبته المئوية (75) إلا أنه احتل المرتبة الأولى في ترتيب المجالات ثم تلاه مجال التدريس في المرتبة الثانية بمنوسط حسابي قدره (2.09) ونسبة الاولية مئوية قدرها (69.66) أي بمستوى منوسط ليحتل مجال خدمة المجتمع 
ونجد أن نتائج الدراسة تختلف مع نتائج دراسة الصرايرة

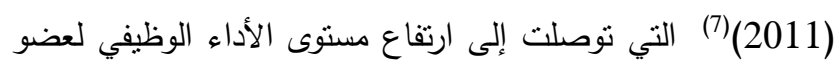

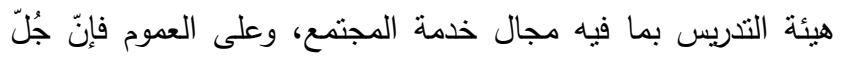

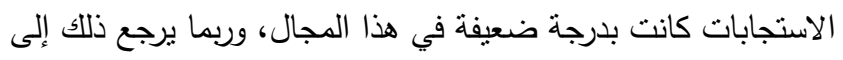

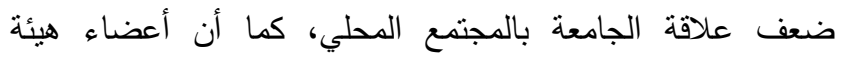

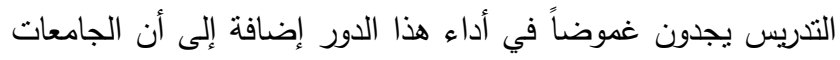

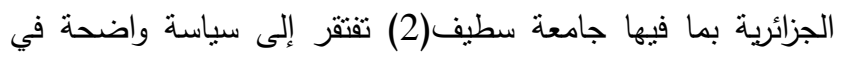
مجال خدمة المجتمع بالرغم من وجود نصوص في قانون الجامعات

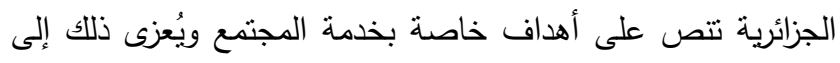
أن القائمين على الكليات يركزون على تتفيذ أنشطة التدريس والبحث وإهمال بقية الوظائف.

\section{2 عرض ومناقشة نتائج التساؤل الثاني:}

والذي ينص على: هل نوجد فروق ذات دلالة إحصائية عند مستوى الدلالة (2> 0.05) في مستوى الأداء الوظيفي لأعضاء هيئة التدريس بجامعة سطيف (2) في مجالات التدريس ،البحث العلمي

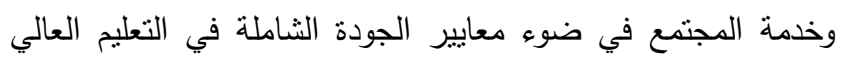
تُعزى لمتغيرات ( الجنس، الرتبة الأكاديمية).

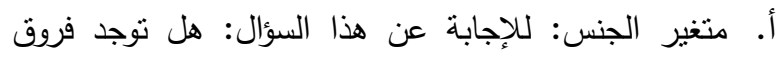

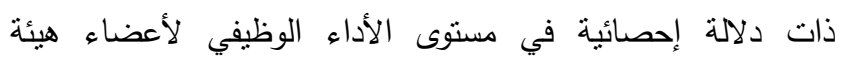

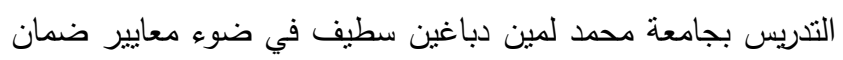

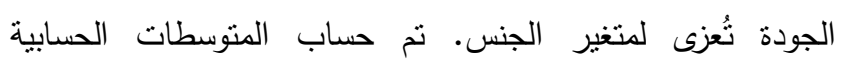
والانحرافات المعيارية على مجالات الدراسة ككل، ولبيان الفروق الدالة

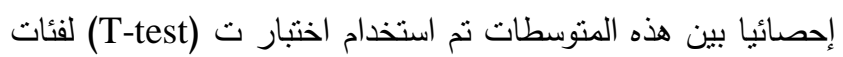
عينة الدراسة موزعة حسب الجنس، والجدول التالي يوضح ذللك.

جدول رقم (04): يوضح نتائج اختبار T test للفروق لاستجابات أفراد عينة الاراسة حسب متغير الجنس.

\begin{tabular}{|c|c|c|c|c|c|c|c|}
\hline \multirow{2}{*}{ الدلالة } & \multirow{2}{*}{ قيمة } & \multicolumn{2}{|c|}{ إناث } & \multicolumn{2}{|c|}{ ذكور } & \multirow{3}{*}{ المجال } & \multirow{3}{*}{ الرقم } \\
\hline & & 103 & العدد & 82 & العدد & & \\
\hline & & المعياري & الحسابي & المعياري & الحسابي & & \\
\hline 0.07 & 1.82 & 1.65 & 2.17 & 0.70 & 2.01 & التدريس & 01 \\
\hline 0.82 & 0.23 & 1.53 & 2.34 & 1.23 & 2.16 & العلمي & 02 \\
\hline 0.06 & 1.92 & 0.69 & 1.81 & 0.86 & 1.69 & خدمة & 03 \\
\hline 0.95 & 1.33 & 1.29 & 2.10 & 0.93 & 2.04 & لي & \\
\hline
\end{tabular}

المصدر : من إعداد الباحثين.

يتضح من الجدول رقم (04) أن الفروق في المنوسطات بين

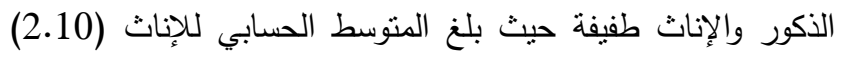

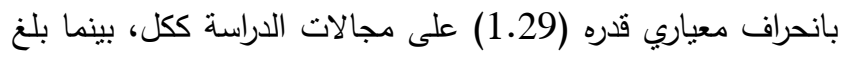

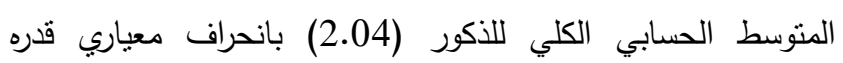

تنتشر بالثكل المطلوب مقارنة مع الجامعات الأجنبية وبعض الجامعات العربية التي لها باع طويل في تطبيقات الجودة.

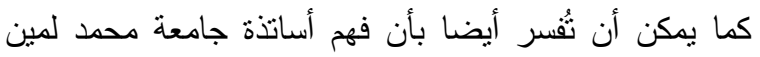
دباغين للجودة يعود للاراسات والأبحاث النظرية أكثر منه للممارسات الميدانية (تطبيقات)، وهناك من لا يعرف معايير جودة عضو هيئة التدريس، ولا متطلبات جودة ممارسة مهامه الوظيفية، إضافة إلى كثرة

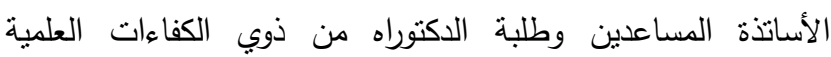

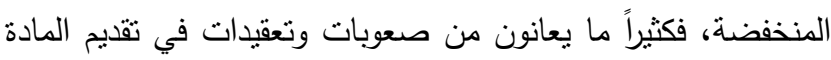
العلمية التي تفوق مستواهم وخبرتهم، حيث نتحول هذه الصعوبات إلى نى معوقات تواجه الطلبة في فهم الحقائق العلمية.

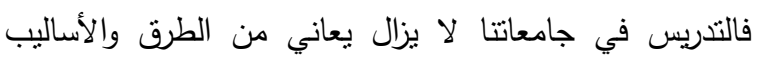

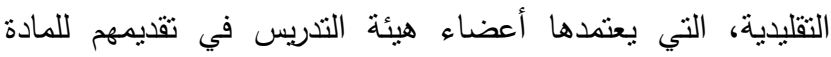

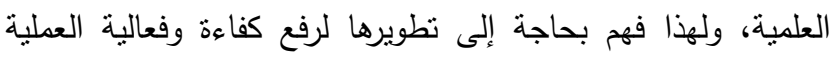
التعليمية ومنه تتمية المهارات الفكرية والعلمية وغيرها عند الطلبة، ولا

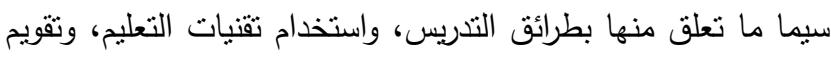

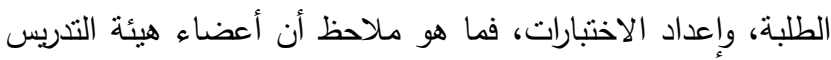
بجامعة سطيف2 يعانون من ضعف في استخدام تكنولوجيات التعليم

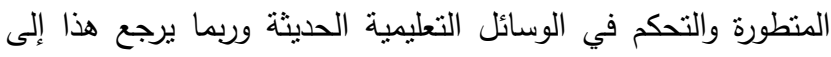

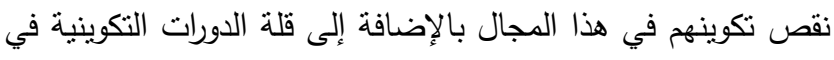

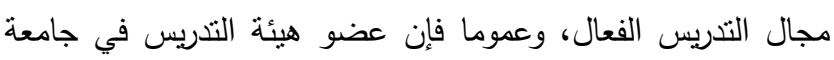
محد لمين دباغين يفتقر لبعض المهارات التي تتطلبها جودة الأداء

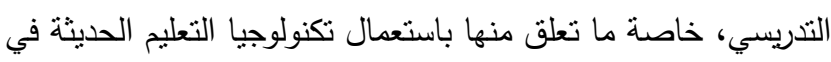
التنريس وتصميم المقررات الإلكترونية واعتماد الوسائل التعليمية

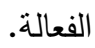

أمّا ما تعلق بالبحث العلمي فنجد قلة مراكز البحوث المتميزة

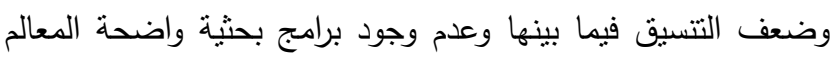

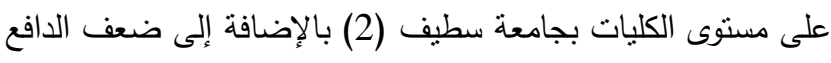
لإجراء بحوث تخدم احتياجات الاقتصاد الوطني لعدم وجود مستخدمين ومستفيدين من هذه البحوث، وقلة الحوافز المادية والمعنوية الإنية وضعف الاهتمام بتوظيف نتائج الأبحاث العلمية كما لا يمكن تجاهل

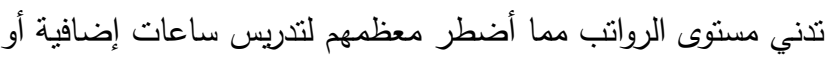

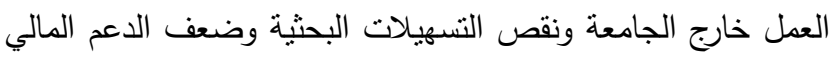

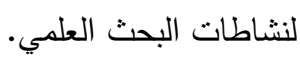
أخيراً وفيما يتعلق بخدمة المجتمع والذي جاء في المرنبة الأخيرة

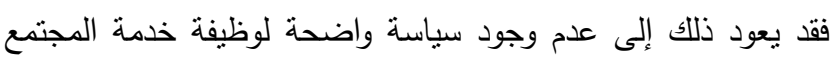

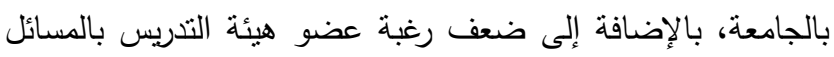

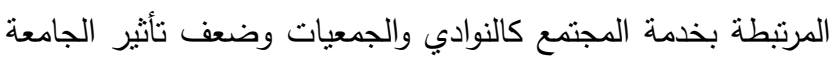
بصفة عامة في الحراك الاجتماعي واقتصار الهمامها على المسائل وضلئل التنريبية والبحثية. 
تقييم الأداء الوظيفي لأعضاء هيئة التدريس بجامعة سطيف (2) في ضوء معايير ضمان الجودة من وجهة نظرهم.

لمتغير الرتبة الأكاديمية. وريما يعود ذلك إلى أن التنريس يُعتبر

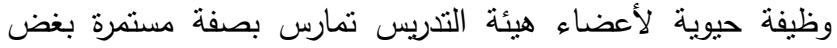
النظر عن مستواهم العلمي. - اعي.

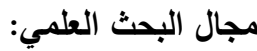
جدول رقم (06): نتائج اختبار كروسكال في مجال البحث العلمي حسب متغير

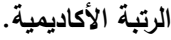

\begin{tabular}{|c|c|c|c|c|c|}
\hline \multicolumn{6}{|c|}{ مجــــــــــال البحث العلمي } \\
\hline مستوى الدلالة & قيمة كا2 & درجة الحرية & متوسط الرتب & العدد المد & الرتبة \\
\hline \multirow{3}{*}{0.03} & \multirow{3}{*}{7.42} & \multirow{3}{*}{2} & 65.89 & 70 & أستاذ مساعد \\
\hline & & & 77.46 & 105 & أستاذ محاضر \\
\hline & & & 85.16 & 10 & أستاذ التعليم \\
\hline
\end{tabular}

المصدر : من إعداد الباحثين

من خلال النتائج المبينة في الجدول رقم (06) يتضح أن هناك تفاوناً بين منوسطات رتب استجابات أفراد عينة الدراسة حيث سجل أستاذ التعليم العالي أعلى متوسط رثب بن بلغ (85.16)، ثم يليه أستاذ محاضر بمنوسط رتب (77.46)، ثم أستاذ مساعد (65.89)، كما تبين النتائج أيضا أن قيمة كا² المحسوبة (7.42) أكبر من قيمة كا² المجدولة (5.99) عند درجة حرية 2 ومستوى دلالة (2> 0.05)،

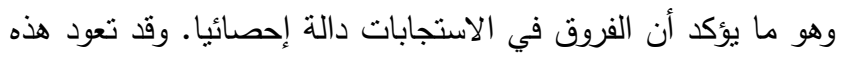

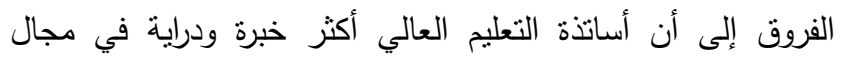
البحوث العلمية، كما أن لهم باعاً طويلةً في ممارسة الأبحاث الأكاديمية، ويمكن القول إنّ نشاطهم في هذا المجال أوسع بحكم اقدميتهم في العمل التي أكسبتهم تلك الخبرة مقارنة بالأساتذة الآخرين.

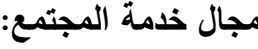

جدول رقم (07): نتائج اختبار كروسكال في مجال خدمة المجتمع حسب متغير الكلية.

\begin{tabular}{|c|c|c|c|c|c|}
\hline \multicolumn{6}{|c|}{ مجـــــــــال خدمة المجتمع } \\
\hline الدلالة & كايمة & الحرية & متوسط الرتب & العدد & المستوى الأكاديمي \\
\hline \multirow{3}{*}{0.09} & \multirow{3}{*}{1.38} & \multirow{3}{*}{2} & 53.96 & 70 & أستاذ مساعد \\
\hline & & & 58.67 & 105 & أستاذ محاضر \\
\hline & & & 60.54 & 10 & أستاذ التعليم العالي \\
\hline
\end{tabular}

المصدر : من إعداد الباحثين.

يتضح من خلا بيانات الجدول (07) أن هناك نقارباً بين متوسطات رتب استجابات أفراد عينة الدراسة حيث سجل متوسط رتب أستاذ التعليم العالي (60.54)، ومتوسط رتب أستاذ محاضر

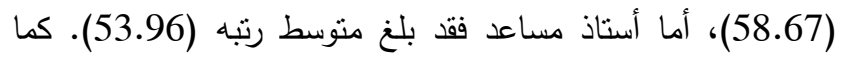

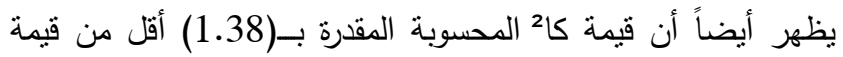
كا² المجدولة التي تساوي (5.99) عند مستوى الدلالة (م>

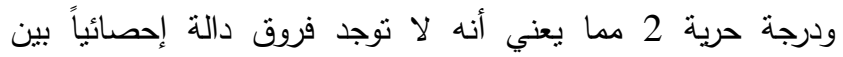

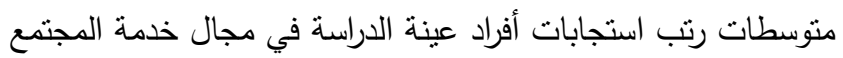

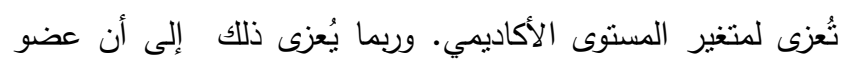

(0.93)، وكلا المتوسطين يندرجان ضمن الفئة المتوسطة التي تنزاوح بين [1.67 -2.33] وبما أن قيمة ت المحسوبة تساوي (1.33) وهي لتاني

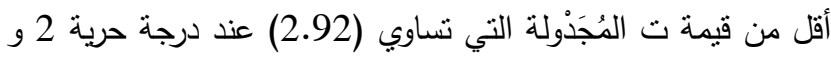

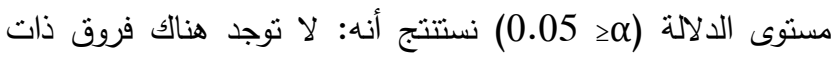
دلالة إحصائية في مسنوى أداء أعضاء هيئة التدريس في جامعة محمد لمين دباغين سطيف (2) في مجال التدريس والبحث العلمي وخدمة المجتمع تُعزى لـتغير الجنس.

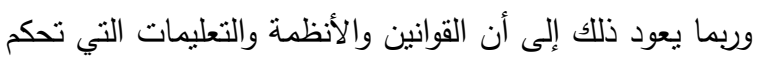
العمل الإداري، وتحدد الواجبات والمهام الوظيفية لا تفرق بين الذكور

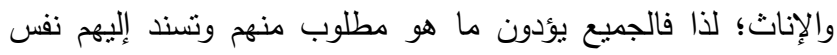
الوظائف والمهام بغض النظر عن جنسهم، كما قد يعود ذلك إلى أنهح يعملون تحت مناخ تتظيمي واحد. وتتفق هذه النتيجة مع دراسة لئن

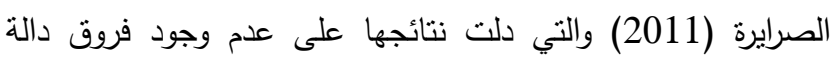
إحصائيا في مستوى الأداء الوظيفي لأعضاء الهيئات التدريسية في الجامعات الأردنية تُعزى لمتغير الجنس. ب. متغير المسنوى الأكاديمي: للإجابة عن السؤال التالي: هل لإنل

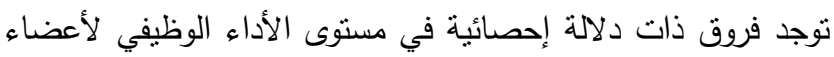
هيئة التنريس بجامعة محمد لمين دباغين سطيف في مجالات (التدريس، البحث العلمي، وخدمة المجتمع) في ضوء معايير ضمان الجودة تُعزى لمتغير : المستوى الأكاديمي؟

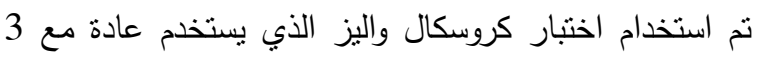

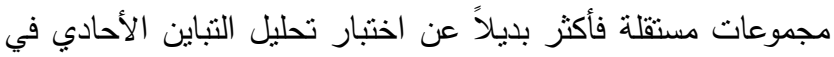

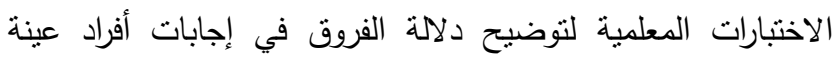
الدراسة حسب متغير المستوى الأكاديمي وجاءت النتائج كالتالي:

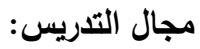

جدول رقم (05): نتائج اختبار كروسكال في مجال التريس حسب متغير الرتبة

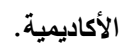

\begin{tabular}{|c|c|c|c|c|c|}
\hline \multicolumn{6}{|c|}{ مجــــــــال التدريــــــــــــ } \\
\hline مستوى الدلالة & قيمة كا² & درجة الحرية & متوسط الرتب & 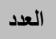 & الرتبة \\
\hline \multirow{3}{*}{0.07} & \multirow{3}{*}{3.25} & \multirow{3}{*}{2} & 69.43 & 70 & أستاذ مساعد \\
\hline & & & 73.58 & 105 & أستاذ محاضر \\
\hline & & & 75.29 & 10 & أستاذ التعليم \\
\hline
\end{tabular}

المصدر : من إعداد الباحثين.

يتضح من خلال بيانات الجدول (05) أن هناك نقارباً بين متوسطات رتب استجابات أفراد عينة الدراسة حيث سجل منوسط رثب

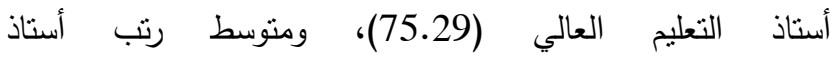
محاضر (73.58)، أما أستاذ مساعد فقد بلغ متوسط رتبه (69.43). كما يظهر أيضاً أن قيمة كا2 المحسوبة المقدرة بـ(5.496) أقل من قيمة كا² الهجولة التي تساوي (5.99) عند مستوى الدلالة (20) 0.05) ودرجة حرية 2 مما يعني أنه لا توجد فروق دالة إحصائياً بين

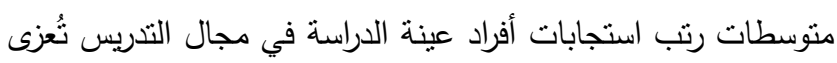


من خلال النتائج المبينة في الجدول رقم (09) يتضح أن أكبر متوسط رتب سجلته كلية العلوم الإنسانية والاجتماعية (62.35)، ثم

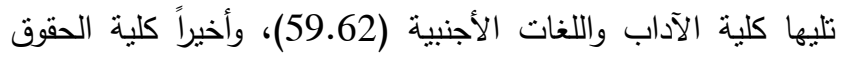

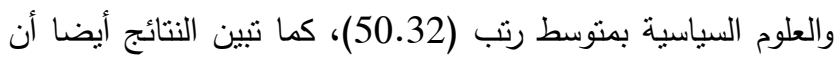
قيمة كا² المحسوبة (4.64) أقلّ من قيمة كا² المجدولة (5.99) عند

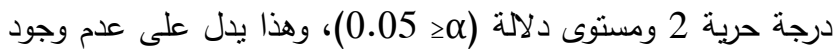
فروق دالة إحصائياً بين متوسطات رثب استجابات أفراد عينة الدراسة في مجال البحث العلمي تُعزى لمتغير الكلية، وربما قد يرجع هذا إلى الى تدني مستوى البحث العلمي في الجامعة عموماً بما فيها الكليات التنابعة لها على حد سواء.

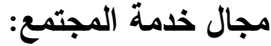

جدول رقم (10): نتائج اختبار كروسكال في مجال خدمة المجتمع حسب متغير الكلية.

\begin{tabular}{|c|c|c|c|c|c|}
\hline \multicolumn{6}{|c|}{ مجـــــــــال خدمة المجتمع } \\
\hline مستوى الدلالة & كاء2 & دالحرية & متوسط & العدد & الكلية \\
\hline \multirow{3}{*}{0.09} & \multirow{3}{*}{1.54} & \multirow{3}{*}{2} & 53.16 & 93 & العلوم الإنسانية والاجتماعية \\
\hline & & & 48.67 & 62 & الآداب واللغات الأجنيبة \\
\hline & & & 55.36 & 30 & الحقوق والعلوم السياسية \\
\hline
\end{tabular}

من خلال النتائج المبينة في الجدول رقم (10) يتضح أن أكبر منوسط رتب سجلته كلية الحقوق والعلوم السياسية (55.36)، ثم تليها كلية العلوم الإنسانية والاجتماعية (53.16)، وأخيراً كلية الآداب واللغات الأجنبية بمتوسط رتب (48.67) ، كما تبين النتائج أيضاً أن الأن الباتية قيمة كا² المحسوبة (1.54) أقلّ من قيمة كا² المجدولة (5.99) عند

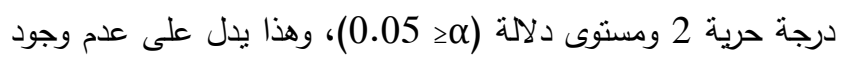
فروق دالة إحصائياً بين منوسطات رتب استجابات أفراد عينة الدراسة

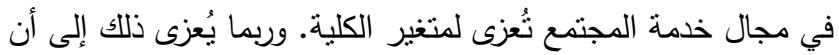
مستوى خدمة المجتمع ضعيف في الجامعة عموماً بما فيها الكليات التابعة لها. وبناءً على ما تقدم نستتتج عدم وجود فروق دالة إحصائيا في مستوى الأداء الوظيفي لأعضاء هيئة التدريس بجامعة محمد لكين دباغين سطيف في مجالات (التدريس، البحث العلمي، وخدمة المجتمع) في ضوء معايير ضمان الجودة تُعزى لمتغير الكلية.

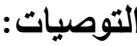

وبعد التأكد من المستوى المتوسط لأداء الأساتذة بالجامعة في

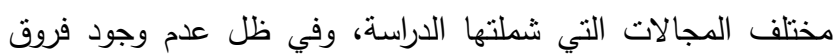
ذات دلالة إحصائية في الأداء بين الأساتذة تبعا لمتغيرات الجنس،

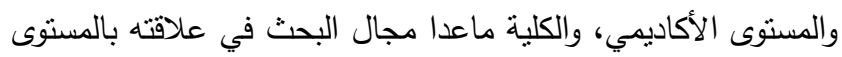

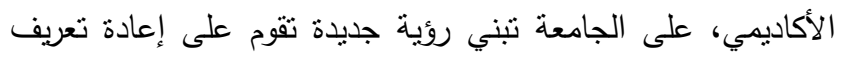

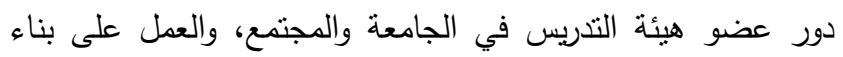

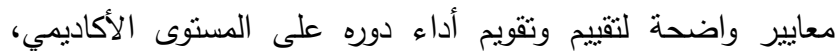

هيئة التدريس لا يولي وظيفة خدمة المجتمع أهمية كبيرة مقارنة مع وظائفه الأخرى كونها غامضة نوعاً ما وغير واضحة المعالم بالنسبة له

ج. متغير الكلية: للإجابة عن السؤال التالي: هل توجد فروق ذات دلالة إحصائية في مستوى الأداء الوظيفي لأعضاء هيئة التدريس بجامعة محمد لمين دباغين سطيف في مجالات (التدريس، البحث العلمي، وخدمة الهجتم) في ضوء معايير ضمان الجودة تُعزى لـتغير الكلية؟ نم استخدام اختبار كروسكال واليز الذي يستخدم للمقارنة بين ثلاث مجموعات مستقلة فأكثر في الاختبارات

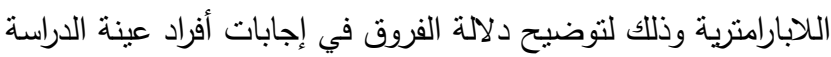
حسب متغير الكلية وجاءت النتائج كالتالي:

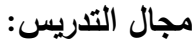

جدول رقم (08): نتائج اختبار كروسكال في مجال التدريس حسب متغير الكلية.

\begin{tabular}{|c|c|c|c|c|c|}
\hline \multicolumn{6}{|c|}{ 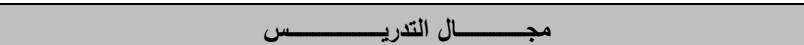 } \\
\hline الدلالة & كا2 & دالحرية & متوسط الرتب & 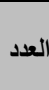 & 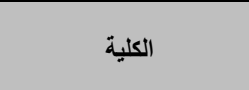 \\
\hline \multirow{3}{*}{0.09} & \multirow{3}{*}{3.84} & \multirow{3}{*}{2} & 67.21 & 93 & العلوم الإنسانية والاجتماعية \\
\hline & & & 59.46 & 62 & الآداب واللغات الأجنبية \\
\hline & & & 52.67 & 30 & الحقوق والعلوم السياسية \\
\hline
\end{tabular}
المصدر : من إعداد الباحثين.

يتضح من خلال بيانات الجدول (08) أن هناك تفاوتاً بين

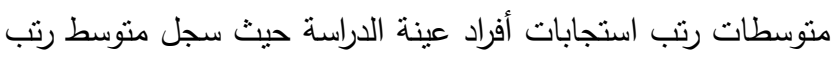

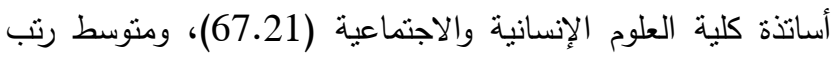
أساتذة كلية الآداب واللغات الأجنبية (59.46)، أما أساتذة كلية الحقوق والعلوم السياسية فقد بلغ متوسط رتبه (52.67) ـ وبالرغم من هذا التفاوت إلا أننا نجد أن قيمة كا² المحسوبة

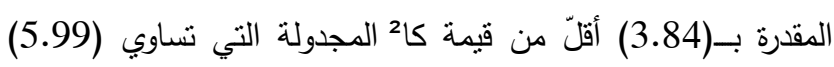

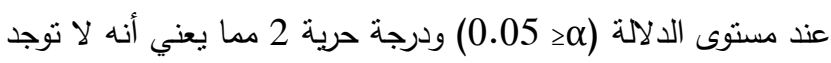
فروق دالة إحصائياً بين منوسطات رتب استجابات أفراد عينة الدراسة الدية

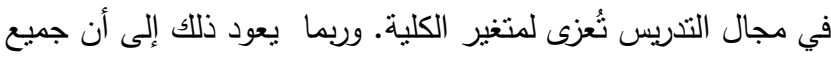

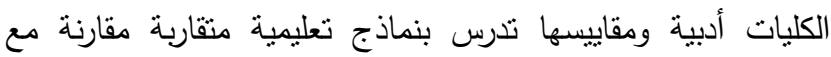
الكليات العلمية التي ربما يختلف التدريس فيها نظراً لطبيعة المادة العلمية المقدمة.

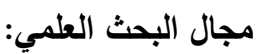
جدول رقم (9):نتائج اختبار كروسكال في مجال البحث العلمي حسب متغير الكلية.

\begin{tabular}{|c|c|c|c|c|c|}
\hline \multicolumn{6}{|c|}{ مجــــــــــال البحث العلمي } \\
\hline مستوى الدلالة & كايمة & الحرجة & متوسط الرتب & العدد & الكلية \\
\hline \multirow{3}{*}{0.06} & \multirow{3}{*}{4.64} & \multirow{3}{*}{2} & 62.35 & 93 & العلوم الإنسانية والاجتماعية \\
\hline & & & 59.62 & 62 & الآداب واللغات الأجنيية \\
\hline & & & 50.32 & 30 & الحقوق والعلوم السباسية \\
\hline
\end{tabular}
المصدر : من إعداد الباحثين. 
تقييم الأداء الوظيفي لأعضاء هيئة التدريس بجامعة سطيف (2) في ضوء معايير ضمان الجودة من وجهة نظرهم.

4. Al-Kharabsheh, Omar Muhammad Abdullah (2012), The Hashemite Kingdom of Jordan's Experience in Quality Assurance and Academic Accreditation Standards in Educational Colleges, The Second Arab International Conference on Quality Assurance in Higher Education, Gulf University, Kingdom of Bahrain.

5. Al-Khatib, Ahmad and Al-Khatib Radah, (2010), Accreditation and Quality Control in Arab Universities, modern book science, first edition, Irbid, Jordan.

6. Al-Naqari, Emilia Mahmoud and AlTarawneh, Yusuf (2018). The Degree of Jordanian Universities Achieving Quality Assurance Standards From the Viewpoint of Faculty Deans and Heads of Academic Departments Therein, Journal of Educational Sciences Studies Volume 45 No. 3, Jordan.

7. Al-Sarayreh, Khaled Ahmad, (2011), Career Performance of Faculty Members in Jordanian Public Universities From the Viewpoint of Department Heads in Them, Damascus University Journal - Volume 27 First + Second Number.

8. Al-Sharman, Munira and Safaa Ja`fara, (2014), The Degree of Job Satisfaction for Faculty Members and its Relationship to the Level of Performance, Al-Manara Magazine, Volume 20, Issue 1.p. 411/444.

9. Arouet, F.M., (2009) , Competitive Advantage and the New Higher Education Regime, Entelequia. Revista Interdisciplinar, 10, Otoño, pp. 21-35. Retrieved Jan. 15, 2012, rom:

http://www.eumed.net/entelequia/es.art.php?a $=10 \mathrm{a} 0$

10. Badawi, Ahmed Zaki, (1984), Dictionary of Administrative Sciences Terminology, Dar Al-Kitab Al-Masry, , Cairo, Egypt.

11. Badley, G. , (1999), Improving Teaching in British Higher Education' Quality Assurance in Education, 7, (1), pp.35-40.

12. Badri, M.A. and Abdulla, M.H., and Chiam, C. C., Lim, ., Norbaini , A. H, \& Nur, A.O., (2011) ,Towards Excellence in Higher Education -The Experience of Open University Malaysia (OUM), In: Symbiosis International Conference on Open \& Distance Learning, 21-23 Feb 2011, Pune, India.

13. Bashour, Mounir, and Ramzi Salama (2005), Quality Assurance in Arab Universities, Beirut: Lebanese Association for Educational Sciences.

14. Bawab, Radwan, (2015), The Functional and Social Performance of the University Professor in Nizam Al-Almadi, Journal of
والبحثي، والمسؤولية المجتمية، كما يجب ألا ينظر إلى نلك المعايير

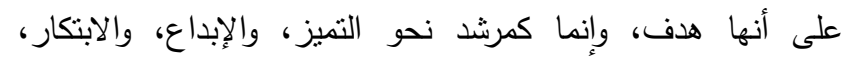

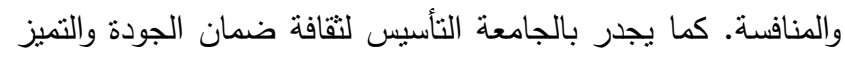

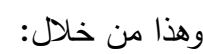

ح إعداد دليل عضو هيئة التدريس يوضح حقوق وواجبات

$$
\text { ومسؤوليات أعضاء هيئة التدريس. }
$$

ل ل بناء معايير واضحة ومحددة لاختيار عضو هيئة التدريس،

تتضمن السمات الثخصية، والسمات الاجتماعية، والقيادية،

$$
\text { والسمات الأكاديمية، والمهارية }
$$

ا إنثاء مركز للتمية المهنية لأعضاء هيئة التدريس اللهارية

بالجامعة، للقيام بمهام إعداد برامج تدرييية محددة ومجدولة للتتمية المهنية لهيئة التدريس بشكل دوري ومستمر .

التنويع في أساليب التقييم المستخدمة لأعضاء هيئة

التثريس في الجامعات بحيث يشارك فيها المدرس نفسه

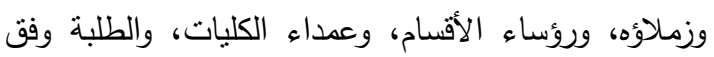
أسس موضوعية مقبولة من الأطراف كُّها.

الحرص على تتفيذ جميع مهام التدريس من خلال وضع منع الاطراف

خطة دراسية تتسم بالجودة وتتفيذها باستخدام طرائق

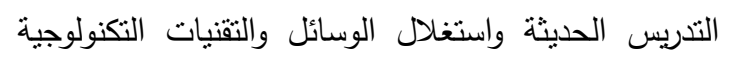

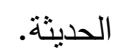

تثجيع أعضاء هيئة التدريس على النشر في المجلات العلمية الدولية

ل تحفيز أعضاء هيئة التدريس للمساهمة في برامج المسؤولية

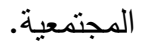

تزويد أعضاء هيئة الندريس بالتغذية الراجعة حول أدائهم

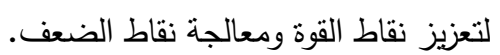

\section{References:}

1. Abu Al-Rab, Imad and et al., (2010), Quality Assurance in Educational Institutions, Research and Studies, (1st edition), Dar AlSafa for Publishing and Distribution, Amman, Jordan.

2. Abu Radhi, Sahar Muhammad Muhammad, (2015), A Proposed Perception of Standards for Quality Assurance and Institutional Accreditation in Saudi Schools in the Light Of Global Trends, the Arab Journal for Quality Assurance of Higher Education Volume 8 No. 19.

3. Akan, O., Allen, R.S, Helms, M.M., \& Spralls, S.A., (2006), Critical Tactics for Implementing Porter's Generic Strategies, Journal of Business Strategy, Vol. 27, No. 1, pp. 43-53. Retrieved Jan. 25, 2012, from: http://www.emeraldinsight.com 
Tawfiq, Ali Alam, (2008), Professional Development for Faculty Members, an Introduction to Comprehensive Quality in University Education, The Arab Journal for Quality Assurance of University Education.

19. Raqqad, Saliha, (2014), Application of the Quality Assurance System in Algerian Higher Education Institutions, its prospects and constraints, unpublished doctoral thesis, University of Setif, Algeria.

20. Zargan, Layla, (2013), A Training Program Proposal for University Faculty Members in Light of the Comprehensive Quality Standards in Higher Education, unpublished doctoral thesis, University of Setif, Algeria.
Social and Human Sciences, University of Ouargla, Vol. (11) No. (4).

15. Brahimi, Soumaya, (2006), Reform of Higher Education and Scientific Research, MA Thesis in Sociology of Development, University of Biskra, Unpublished, Algeria.

16. Hilal, Mohamed Abdel-Ghani, (1996), Performance Management Skills, Performance Development and Development Center, Cairo, Egypt.

17. Mwafak, Asma, (2015), The Quality of the Teaching Performance of the University Professor from the Students' Point of View, unpublished master thesis, University of Batna, Algeria.

18. Radman, Muhammad Saeed Ghaleb and 